\title{
JESUCRISTO, PROTOTIPO DE JUSTICIA Y MARTIRIO, A FAVOR DE LOS POBRES Y MARGINADOS
}

\author{
Jesus Christ, Paradigm of Justice and Martyrdom, \\ in Favor of the Poor and Marginalized \\ Jesus cristo, protótipo de justiça e martírio, \\ em favor dos pobres e marginalizados
}

Kreti Sanhueza, SSpS

\section{Resumen}

Este artículo expone un breve estudio acerca del significado que alcanza la persona de Jesucristo en cuanto siervo sufriente frente a la realidad de pobreza y marginación que viven los pueblos latinoamericanos. Para ello se ha tenido en cuenta el análisis de la praxis de Jesús, su anuncio del reino, su muerte y su resurrección, en clave de justicia y martirio, teniendo como base el pensamiento cristológico de Jon Sobrino. Queda de manifiesto que ante una realidad de pobreza y marginación, la aspiración a la vida, muchas veces, es castigada con

1 Kreti Soledad Sanhueza Vidal. Chilena. Religiosa Misionera Sierva del Espíritu Santo. Doctora en Teología. Profesora de la Facultad de Teología de la Pontificia Universidad Católica de Chile. Correo: ksanhuez@uc.cl. ID orcid.org/000-003-I8I3-9046.

Artículo recibido el 29 septiembre de 2015 y aprobado para su publicación el 1 marzo de 2016. 
la opresión y la muerte; así sucedió con Jesús, así acontece con los cristianos y el pueblo pobre de América Latina. Por eso, en este estudio se ha podido establecer una relación teológicamente intrínseca entre la cruz, la justicia y el martirio, alcanzados por la muerte de Jesús, y la cruz, la justicia y el martirio asumidos por el pueblo pobre y marginado.

\title{
Palabras clave
}

Jesucristo, Justicia, Martirio, Siervo sufriente, Pobres, Marginados, Reino de Dios.

\begin{abstract}
The article presents some reflections about the meaning of Jesus Christ as 'suffering servant' in relation to the reality of poverty and marginalization experienced by Latin American countries. In order to achieve such a purpose, the article considers the analysis of the praxis of Jesus, his announcement of the Kingdom of God, and his death and resurrection. Such an analysis is made based on Jon Sobrino's Christological thought, having as key concepts Justice and Martyrdom. It is revealed that in a reality of poverty and marginalization, hope for life is penalized in several occasions with repression and death. Jesus also experienced this situation. Therefore, a theologically intrinsic relation is established between the cross, justice and martyrdom as are revealed in the death of Jesus and as are assumed by the poor and marginalized.
\end{abstract}

\section{Keywords}

Jesus Christ, Justice, Martyrdom, Suffering Servant, Poverty, Marginalization, Kingdom of God.

\section{Resumo}

Este artigo expóe um breve estudo sobre o significado que alcança a pessoa de Jesus Cristo, enquanto servo sofredor, diante da realidade de pobreza e marginalização que vivem os povos latino-americanos. Para isto se analisou a práxis de Jesus, seu anúncio do reino, sua morte e sua ressurreição, em clave de justiça e martírio, tendo como base o pensamento cristológico de Jon Sobrino. 
É notório que, ante uma realidade de pobreza e marginalização, a aspiraçáo à vida muitas vezes é castigada com a opressáo e a morte; assim sucedeu com Jesus, assim acontece com os cristáos e o povo pobre da América Latina. Por isso, neste estudo se pôde estabelecer uma relação teologicamente intrínseca entre a cruz, a justiça e o martírio, alcançados pela morte de Jesus, e a cruz, a justiça e o martírio assumidos pelo povo pobre e marginalizado.

\section{Palavras-chave}

Jesus Cristo, Martírio, Servo sofredor, Pobres, Marginalizados, Reino de Deus.

\section{INTRODUCCIÓN}

En el pensamiento cristológico latinoamericano Jesucristo es no solo el núcleo de la fe que se confiesa, sino y sobre todo la persona en quien se cree y a quien se sigue como Aquel que erige el modo de ser cristiano en medio de la historia de los pueblos latinoamericanos.

La cristología de América Latina piensa a Jesucristo en cuanto Jesús de Nazaret, porque se busca confesarlo no solo de palabra sino con la vida. En vista de ello, procura aproximar a los cristianos todo lo que implica su persona y su vida. Trata de hacer accesible el significado de su misión, de su mensaje, de su enseñanza y de todo cuanto hizo y vivió.

Asimismo, la tarea de pensar a la persona de Jesucristo contempla aquellos elementos bíblico-cristológicos que lo instituyen como no sólo digno sino posible de imitar, de hacer de su forma de vida y misión la propia opción de vida, y que invita a un compromiso real y fiel con las personas, especialmente con los pobres y marginados de la historia.

Por eso, el hablar sobre la justicia y el martirio adquiere su importancia en la misma persona de Jesucristo, por cuanto la fe cristiana y todo cristiano, como afirma Pablo, proclama que cree y sigue a un Cristo crucificado, escándalo para los judíos y locura para los gentiles, pero para los que se reconocen llamados, Cristo es fuerza y sabiduría de Dios (cf. 1Cor 1,23). 
Este escrito intenta reflexionar analíticamente el significado que adquiere la persona de Jesucristo para los pueblos de América Latina, a partir del pensamiento cristológico de Jon Sobrino. Se expone, en primer lugar, una mirada ordenada sobre aspectos que reflejan la realidad históricosocial y eclesial de América Latina. Luego, se examinan algunos elementos cristológicos latinoamericanos que ayudan auscultar el sentido de justicia y martirio que conlleva la praxis, el mensaje, la muerte y la resurrección de Jesús. Por último, se reflexionar sobre la importancia de dar continuidad a la propuesta de Jesús, en clave de un anuncio fehaciente del Evangelio que contempla el compromiso con la realidad de pobreza y marginación que siguen viviendo la mayoría de los pueblos de Latinoamérica.

\section{LA JUSTICIA EN EL CONTEXTO ECLESIAL- TEOLÓGICO DE LATINOAMÉRICA}

Desde un punto de vista antropológico, se puede decir que la justicia dice relación con el orden desde el que se desarrollan las relaciones humanas o el orden al cual se ajusta la conducta humana. Si se tiene en cuenta este alcance del término, se puede partir considerando, a lo menos, dos sentidos de orientación del significado que tiene dicho 'orden' en las relaciones sociales. De una parte, la justicia como conformidad de la conducta a una norma; de otra, la justicia como eficiencia de una norma (Abbagnano, 2007, p. 682).

La aproximación teológica a la justicia en América Latina se hace en vista a la necesidad que expresa el cristiano de comprender cómo está presente Dios y cómo se revela en medio de la pobreza y la marginación que viven los pueblos en el continente. Se trata, por tanto, de buscar el significado que tiene en clave teológica la ordenación de las relaciones humanas, sociales o comunitarias que se viven en el continente.

La Escritura, más que plantear la justicia como una característica humana propiamente tal, habla de justicia como una acción salvadora de Dios. De acuerdo a lo expuesto por la exégesis, en el Antiguo Testamento (AT) Dios obra con base en las normas que Él ha establecido "por su propia naturaleza y por las relaciones" que voluntariamente ha contraído con la humanidad. Por eso, Dios es justo porque actúa conforme a lo que ha dicho y hecho con su pueblo Israel, y de acuerdo a la promesa dada (León-Dufour, 1982, 
p.460). En el Nuevo Testamento (NT) la justicia dice relación con "la acción misericordiosa de Dios” por medio de la persona de Jesús. Por él se comprende la vida cotidiana "como un camino de justicia y justificación", camino que se inicia por la iniciativa gratuita y generosa de Dios (Medina, 2007, pp.1001129). Así, Jesús exhorta a sus discípulos y seguidores a practicar la justicia. Si bien, Jesús no habla del tema de la justicia de manera directa, porque su centro es el reino, sin embargo no es ajeno a ella. Invita a sus discípulos a vivir la justicia cotidiana, a orientar sus vidas en la dirección del cumplimiento de los mandamientos de Dios (León-Dufour, 1982, p.462).

La reflexión teológica y cristológica latinoamericana sobre la justicia y el martirio se orienta a partir de lo antes señalo; esto es, se muestra en la teología latinoamericana una estrecha relación entre: los mandamientos -la norma-, las relaciones de Dios con la humanidad y de las personas entre sí, vida, misión y fin de Jesús, y el testimonio cristiano inserto en una realidad de pobreza y marginación.

\section{Algunos aspectos de la realidad social de América Latina en clave eclesial}

Es sabido por todos que uno de los aspectos que más caracteriza la realidad de los pueblos latinoamericanos es la pobreza, que en ciertas etapas históricas tanto como en ciertos lugares geográficos adquiere rasgos de miseria. Ya la II Conferencia General del Episcopado Latinoamericano en 1968 aseveraba que los muchos estudios realizados "sobre la situación del hombre latinoamericano... describen la miseria que margina a grandes grupos humanos. Esa miseria, como hecho colectivo, es una injusticia que clama al cielo" (Medellín, 1968, p.25). Al parecer, lo que se enunciaba en la década del sesenta sigue vigente en la primera década del nuevo milenio, si bien, en un nuevo contexto histórico, social y cultural. La V Conferencia General del Episcopado, celebrada en el año 2007, en Aparecida, Brasil, expresa que la globalización, "conducida por una tendencia que privilegia el lucro y estimula la competencia... sigue una dinámica de concentración de poder y de riquezas en manos de pocos, no sólo de los recursos físicos y monetarios, sino sobre todo de la información y de los recursos humanos, lo que produce la exclusión de todos aquellos no suficientemente capacitados... aumentando las desigualdades que marcan tristemente nuestro continente y mantienen en la pobreza" (Aparecida, n 62) a una gran mayoría de personas. 
Parece ser que actualmente el movimiento del péndulo oscila ya no sobre desarrollo y subdesarrollo, como sucedía en la década del setenta, sino más bien sobre el mercado neoliberal y el estado de bien social, puesto que lo que es característico del mundo, adquiere en Latinoamérica rasgos propios. Se está viviendo al ritmo del mercado de la privatización, pero ahora no sólo en la línea de los bienes privados, sino que también el mercado neoliberal arrastra consigo la privatización de las empresas públicas (Lesbanpin, 2006, p.56). De esa manera, el movimiento pendular lo fija la atracción que ejerce el neoliberalismo. Es decir, las estructuras de convivencia o no convivencia social lo rigen los derechos de propiedad y de capacidad para crear condiciones de competencia de mercado (Atria et al., 2013, p.13). La misma expresión de "ciudadano" en ese entorno sirve más bien para "identificar a organizaciones no gubernamentales o movimientos sociales que actúan políticamente sin mediación institucional" (Atria, 2013, p.34). Asimismo, para el neoliberal la política consiste en el desarrollo de "formas de negociación que son conducidas por individuos autointeresados" (Atria, 2013, p.36).

La manera cómo afecta el movimiento de mercado neoliberal en los países del continente lo dejan ver los estudios llevados a cabo por la CEPAL. En el año 2005 señala que, en relación a la pobreza, el 40,6\% de la población vive en situación de pobreza y un 16,8\% se encuentra en situación de pobreza extrema o en la indigencia ${ }^{2}$. En relación con ello, unos 213 millones de habitantes de América Latina y del Caribe viven bajo la línea de la pobreza y otros 88 millones viven en situación de indigencia (Zaffaroni, 2006, p.66).

Aparecida, por su parte, señala que la globalización no es capaz de dejarse mover por valores objetivos que estén más allá del mercado. La pobreza y extrema pobreza que genera puede reconocerse en las comunidades

2 Cabe considerar que la CEPAL, en su Informe sobre la pobreza en América Latina del año 2014, indica que si bien ésta ha vivido un descenso en los índices de pobreza, entre los años 2005 a 2012, liderado, principalmente, por países como Chile, Paraguay, El Salvador, Colombia y Perú, actualmente se ha estancado. Asimismo, señala que "la cifra de pobreza del año [2014] se traduce en 167 millones de personas que viven en esa condición, lo que significan cinco millones de pobres más que en el 2012”. Por tanto, pareciera que la realidad socio-económica de América Latina todavía no ha llegado a una dinámica de vida estable y continua de superación de la pobreza y de la marginación de las personas. http://www.portafolio.co/economia/informe-la-pobreza-america-latina2014-segun-cepal. 
indígenas y afroamericanas que, muchas veces, no son tratadas en igualdad de condiciones ni de dignidad. Participan de la pobreza las mujeres excluidas en razón de su sexo o raza, los jóvenes que reciben una educación de baja calidad (Aparecida, $\mathrm{n}^{\circ}$ 65), los migrantes que se ven forzados a salir de sus países en busca de nuevas y mejores oportunidades (Aparecida, no 73).

Visto ello, se puede decir que la justicia, en cuanto realidad que clama al cielo, sigue siendo una tarea pendiente y un elemento catalizador de los modos -que pueden llegar a traducirse en normas- en cómo se establecen las relaciones entre sociedades de países, y entre sociedades al interior de una misma nación. La realidad de pobreza del continente, que llega en muchos lugares al nivel de miseria, sigue siendo un rasgo característico de la vida de los pueblos de América Latina, no sólo por su expresión física en cuanto carencias de tipo económico, cultural y social, sino y sobre todo, porque condiciona, de un modo permanente, las relaciones humanas, ya sea a nivel de personas, de sociedades y de países. Debido a ello, tanto la vida como la disposición de las relaciones están marcadas por una injusticia que tergiversa la norma de la conducta humana y que impide la eficacia de un orden social justo. En medio de esa forma de vida colectiva injusta, los cristianos como los teólogos entienden que seguir a Jesucristo y confesar que Dios se manifiesta en medio de esta historia, exige de los mismos asumir dicha realidad histórica como lugar de praxis y de anuncio de la confesión cristiana; esto es, se trata de pensar la fe y asumir el compromiso cristiano en un contexto de pecado que exige, tanto de la vida cristiana como del pensamiento teológico, exponer la conversión en perspectiva de una vida creyente encarnada.

\section{JUSTICIA Y MARTIRIO EN LA CRISTOLOGÍA LATINOAMERICANA}

De acuerdo con los acontecimientos que marcan la historia de América Latina, parece no ser posible buscar y trabajar por la justicia sin poner a disposición la propia vida. Por eso, al hablar de justicia se hace necesario hablar, al mismo tiempo, de martirio. Ambos aspectos, en el ámbito de la praxis cristiana, se han desarrollado en una mutua correlación al momento de intensificar la solicitud de justicia, cuando se quiere hacer de ella un orden constitutivo de la forma de vida como nación o sociedad. 
En ese sentido, la cristología de Jon Sobrino es la que mejor expresa la conexión existente entre justicia y martirio vivido por Jesús y justicia y martirio vivido por el pueblo creyente. En el caso de Jesús, se propone aquí la línea teológica de justicia a partir de la justicia salvífica de Dios que expone el NT. Respecto del martirio, se sigue la línea teológica del testimonio, disposición que va unida intrínsecamente a la persona del mártir y que, por lo mismo, se trata de un testimonio dado con la propia sangre.

\section{Realidad humana y reino de Dios}

El contexto cristológico de la justicia y el martirio está dado por la misión de Jesús. Aquello a lo cual, según el testimonio de los Sinópticos, Jesús dedica su vida y es el punto de partida de su ministerio público, es su anuncio del reino de Dios. La llegada del reino, su cercanía y el modo como se hace presente en medio del pueblo es el escenario en donde la solicitud de justicia y el testimonio de vida, por el martirio, alcanzan su significado. Lo que es el núcleo de la misión de Jesús es lo que se convierte en su mensaje y en su praxis de vida. Por tanto, es el núcleo de su misión lo que manifiesta la razón de pedir para vivir la justicia, y de morir, si es necesario, con tal de alcanzarla para los seres humanos.

Hay algo en la cuestión del reino que sitúa a éste como escenario de la justicia y martirio de Jesús. Ese algo dice relación con lo que comporta el reino. Jesús no está interesado en definir lo que es el reino de Dios, sino en mostrar cómo llega y cómo revela a Dios actuando en medio de la historia del pueblo. Por eso, como señala Sobrino, el reino es gracia de Dios, se anuncia a los pobres y trae consigo la exigencia de la conversión.

En cuanto gracia, el reino viene por la iniciativa de Dios, por lo que no surge por una decisión humana, sino que se acerca por la gratuidad de Dios; es un don que hay que pedir: venga a nosotros tu reino. En cuanto que es don, regalo, el reino es buena noticia, porque comporta algo que le hace bien al ser humano, que le es favorable y que le otorga alegría. Asimismo, que el reino de Dios es gracia se manifiesta con la persona de Jesucristo, porque llega con él y en él aparece como salvación. La salvación que significa el reino se expresa no sólo por medio de palabras sino también por medio de hechos. Se trata de acciones que pertenecen a la realidad divina; es Dios quien actúa y, en cuanto actúa, cambia la realidad sobre la que ejerce su 
acción; por eso, el anuncio del reino ni Jesús revelan a un Dios-en-sí, sino un Dios-en-la-historia, como enfatiza Sobrino, y por lo mismo, como el Dios de un pueblo.

El reino de Dios, en cuanto anuncio, tiene como los primeros destinatarios a los pobres. Los pobres son, en el pensamiento de Sobrino, los primeros y los privilegiados de la recepción del reino. $\mathrm{Al}$ anunciarlo, Jesús se dirige directamente a los pobres, por eso, indica el teólogo, los evangelios establecen una relación directa entre reino de Dios y pobres. En el modo en cómo anuncia el reino, se puede ver que Jesús establece entre éste y los destinatarios del mismo, una relación de hecho, ya que lo que hace palpable al reino es lo que le sucede a los pobres; en el reino los pobres ven, deja de estar oprimidos y quedan libres de ser cautivos (cf. Lc 4,16ss). Pero además, el reino de Dios establece, a su vez, una relación de derecho con los pobres, puesto que al anunciar Jesús el reino a los pobres, instaura el modo en que debe ser proclamada su venida.

Respecto de la demanda, Sobrino resalta que la participación en el reino de Dios exige conversión. Su proclamación convoca y los que lo escuchan se transforman en oyentes del anuncio del reino. Por tanto, no es suficiente con escuchar, sino que es necesario hacerse oyentes del anuncio del reino, porque sólo de esa forma se le acoge en la propia realidad y se concreta la propia disposición a un cambio radical de vida. El llamado a la conversión que implica el reino, manifiesta la relación directa que tiene éste con el pecado en cuanto que hace parte de la condición humana. En Jesús se descubre el pecado no sólo como negación de Dios, sino también como negación del reino que es gracia. Por eso, la exigencia de conversión que implica la participación en el reino apela a un cambio de conducta sustancial, puesto que el ser humano debe renunciar al poder que lo contrapone a Dios y al poder que lo hace un opresor de otros hombres. Así, con el anuncio del reino Jesús denuncia que existen formas de convivencia social que no se corresponden con la realidad del reino de Dios y que el pecado que comporta dicha convivencia, no sólo se dirige contra Dios, sino también comporta la ruptura de la filiación que se lleva a cabo por medio de la hermandad (Sobrino, 1997, p.40).

Por lo tanto, cabe sostener que el reino de Dios, en cuanto núcleo de la vida y misión de Jesús, declara el orden querido por Dios para la humanidad, en general, y para los pueblos de América Latina, en particular. Asimismo, 
el reino, que es don y gracia de Dios, conlleva una buena noticia que debe ser recibida. Al recepcionarse esa buena noticia, engendra alegría y orienta a las personas en dirección a Dios, permitiéndole actuar en medio de la historia. Así, la realidad del reino, que se hace presente con la persona de Jesucristo, consiste en que Dios ejerce acciones que benefician a las personas, que las liberan, que les dan vida y las salva. Es por eso que el reino de Dios se anuncia preferentemente a los pobres, porque ellos son los primeros y más necesitados de esa acción liberadora y salvadora de Dios; ellos, que son excluidos de participar de relaciones justas que humanizan y garantizan su dignidad de persona querida por Dios. Asimismo, parece ser que son los pobres los primeros que están dispuestos a oír a Jesús, a reorientar su ser y su vida en dirección del reino y a iniciar un cambio radical de vida. Por lo tanto, dejar que el reino de Dios, que llega con Jesucristo, sea en medio de la propia historia humana y de la de los pueblos, significa que hay disposición para vivir relaciones de justicia.

\section{Reino de Dios y antirreino}

La realidad histórico-social de pobreza, de marginación y de ausencia de las condiciones básicas de vida de Latinoamérica no sólo es un "todavía no" del reino, sino que expresa la negación del mismo. A dicha negación se le reconoce como una realidad de pecado, ya que las situaciones que lo niegan, -y que se manifiestan como injusticia, opresión y represión-, no sólo expresan la ausencia de los bienes que trae consigo el reino, sino que es su contraposición. Entonces, como indica Sobrino, el pecado es una realidad que no sólo contradice el reino, sino que por medio de él se establece el antirreino (Sobrino, 1991, p.167).

En América Latina, se puede decir que es esa realidad de pobreza masiva, cruel, injusta, estructural y duradera, como afirma Sobrino, la que expresa el clamor del pueblo por la presencia del reino (Sobrino, 1992, p.49). Pobreza y clamor son realidades inseparables, porque la pobreza coloca al ser humano ante una realidad límite de la cual se quiere liberar. El pobre, además de sufrir la pobreza, vive sometido a estructuras injustas y opresoras que lo mantienen subyugado y en una realidad desde la cual le resulta difícil salir. La pobreza, por tanto, niega y priva a los pobres de sus aspiraciones a una vida humana y humanizadora, ya que condena a las personas a vivir amenazadas continuamente por la muerte. 
En ese sentido, el pensamiento cristológico latinoamericano enfatiza el carácter histórico del reino de Dios. Si bien el reino no puede ser histórico únicamente, por su carácter divino y escatológico, sí lo es por la condición histórica de la realidad humana a la que viene, y por lo mismo, como señala Sobrino, no puede entender ni interpretarse de forma deshistorizada.

A partir de lo dicho, es posible interpretar el contexto histórico-social latinoamericano en clave de pecado, por cuanto que la pobreza y marginación es una realidad que impide a los pobres ejercer el derecho de vivir dignamente y les impide vivir relaciones socio-humanas de justicia, en cumplimiento a la voluntad de Dios. El pecado, que se expresa como pobreza y marginación, impide el ejercicio de la acción salvadora de Dios que llega con el reino; impide el ejercicio de buena noticia de salvación que es el reino. Por eso mismo, a esa realidad de pecado se lo puede entender como un antirreino, ya que no permite que el reino de Dios se instaure en medio del acontecer histórico-social, como el modo de llevar a cabo relaciones de vida en justicia.

\section{Reino de Dios, seguimiento de Jesús y justicia para los pobres}

La llegada del reino que anuncia Jesús y que establece con su mensaje y su praxis en medio de la humanidad, comporta una decisión ante Dios y ante las otras personas: la decisión por el amor a Dios y el amor al prójimo. Es por esa vía, como indica Sobrino, que la venida inminente del reino genera el desenlace del drama de la historia y la superación del antirreino.

Mientras Jesús se dedica a anunciar el reino, el pueblo, representado por la muchedumbre, va en busca de Jesús y lo sigue. Lo hace, asevera Sobrino, porque no existe otro lugar o persona que pueda brindarles salvación. Descubren que en Jesús el reino de Dios no es sólo esperanza, sino certeza. Esa certeza la garantiza la iniciativa y la gratuidad de Dios que no excluye la participación activa de los hombres. El mismo Jesús, como resalta el teólogo salvadoreńo, sirve activamente al reino y los que se hacen oyentes de su anuncio son exigidos a hacer lo mismo.

La participación activa en el reino puede entenderse como una de las razones de porqué Jesús llama a sus discípulos, no sólo para estar con él sino también para servir al reino. El servicio al reino consiste en hacer lo que hace Jesús. Él, de acuerdo a la narración sinóptica, se acercó frecuentemente a los 
marginados de su tiempo, se acercó a los pobres, a los enfermos, a los débiles y a los pecadores; lo hace Jesús no sólo para consolarlos, sino y sobre todo para hacerles justicia. Se acerca y actúa con y sobre ellos para sacarlos de la situación inhumana en que se encuentran; les hace justicia re-creándoles de su estado de deshumanización, como enfatiza Sobrino.

Importante es, en el pensamiento cristológico latinoamericano, tener presente que el pobre y el oprimido no refiere una realidad únicamente individual. Se está en esa condición porque hay disposiciones históricas que lo colocan en una fase de postergación. Por eso, cuando Jesús se dirige al pobre, no le hace justicia sólo en cuanto individuo, sino que desde el débil busca salvar las barreras sociales que hacen del leproso, del endemoniado o del pecador un marginado.

Ese modo de actuar de Jesús despliega una justicia que se fundamenta en una nueva forma de convivencia entre las personas. La justicia llega o se hace posible por la practica del amor a Dios y al prójimo. Así, la justicia cristiana se sustenta y se manifiesta por la eficiencia del amor, y el amor cristiano se evidencia y se hace efectivo en cuanto rechaza el mal y posibilita el bien.

Por tanto, el seguimiento a Jesús conlleva el anuncio de la buena nueva en clave de testimonio de vida. Se trata de participar de la misión de Jesús, de hacerse parte de la instauración del reino al modo como Él mismo lo hace. La propia instauración del reino exige vivir relaciones nuevas de convivencia, llevadas por la conversión y la reconciliación. Es así que al igual que Jesús, todo cristiano -y toda persona que se dispone- es convocado a confesar con su vida que Dios salva, otorgando justicia y generando relaciones recreativas e inclusivas. La justicia de Dios, que es salvadora, se hace reconocible por el cambio de vida que manifiestan las personas, cuando aquellos que no contaban comienzan a ser aceptados, amados e incluidos, activamente, en el ritmo de las relaciones sociales.

\section{LA MUERTE DE JESÚS COMO JUSTICIA Y MARTIRIO}

Las relaciones que inicia Jesús con los pecadores, la acogida y el perdón que les ofrece, se convierte en motivo de escándalo y de indignación para 
los que lo miran con malos ojos, enfatiza Sobrino. Ese acercamiento hacia los pecadores es el modo en que Jesús hace presente el reino, por lo que en lugar de alegrarse, las autoridades judías lo reciben como una provocación, ya que les resulta inaceptable que Jesús instaure un reino donde Dios dé esperanza a los que siempre se han considerado privados de ella. Quienes se consideran herederos de la promesa y poseedores de la esperanza, consideran un escándalo y les resulta indignante el hecho que Dios en Jesús devuelva la dignidad a aquellos a quienes se les había arrebatado, precisamente, por considerárseles fuera de las normas sociales y religiosas de la época. Para la autoridades judías no es posible que Dios se exprese en un amor parcial, misericordioso y recreador para con los pecadores y los pobres, por lo que es necesario que Jesús muera.

\section{La muerte de Jesús en la línea del siervo sufriente}

Una clave de interpretación de la muerte de Jesús está dado en el elemento bíblico-teológico del "siervo sufriente" de Isaías. Esta línea de interpretación es asumida por la cristología de Sobrino para responder al interrogante acerca de por qué muere Jesús. Se trata de una elemento teológico que coge el NT para explicar, en el contexto judío, la relación que existe entre la misión terrena de Jesús y el destino a que llega dicha misión. En vista de ello, el relato neotestamentario refiere algunas de las expresiones que se contienen en el cántico de Isaías, tales como: la oveja llevada al matadero; encontrado entre los malhechores (Is 53,13; par. Lc, 22,37); para que se cumplieran las Escrituras. Dichas referencias ayudan a la narración bíblica de cómo muere Jesús. Sobre ello, Sobrino expone que no se toman, precisamente de los cánticos de Isaías, aquellas expresiones que permiten explicar el sentido de la muerte de Jesús y, por lo mismo, reflejan mejor el significado teológico del "siervo de Yahvé".

En ese sentido, el teólogo salvadoreño rescata otros aspectos de la teología del siervo que permiten comprender por qué muere Jesús y cuál es el significado de su muerte para la humanidad. Isaías 53 expone que el siervo vive y sufre lo que lo toca a causa de acciones humanas: "ha sido herido por nuestras rebeldías, molido por nuestras culpas" (v.8); "llevó el pecado de muchos" (v.12); "soporta nuestras culpas" (v.11), con el fin de alcanzar la salvación de los hombres: "soporta el castigo que nos trae la paz" (v.5c); 
"con sus cardenales hemos sido curados" (v.5d); "por sus desdichas justifica a muchos" (v.11), e "intercede por los rebeldes" (v. 12) (Sobrino, 1991, p.288). La aplicación a Jesús de la imagen del "siervo de Yahvé" que narra Isaías 53, permite entender que la salvación que trae Jesús es una salvación que la alcanza como el "siervo sufriente" que viene a implantar la justicia y el derecho (Sobrino, 1991, p.293). Por lo demás, no hay otra vía que la de tornarse siervo doliente, para erigir la justicia y el derecho en medio del pueblo y de la humanidad.

Jesucristo, por lo tanto, cuando acepta ser llevado "como oveja al matadero" y ser "encontrado entre los malhechores", establece que es precisamente en su entrega donde se revela la contradicción del amar hasta dar la vida y de la incomprensión humana de ese amor. En cuanto siervo sufriente, manifiesta la fidelidad compasiva y misericordiosa de Dios, porque el Hijo no se resta ante la miseria humana que se muestra de manera injusta. Con base en la entrega de la vida que hace Jesús como siervo sufriente, funda el límite hasta dónde es posible llegar para hacer posible la buena noticia del reino y de la voluntad salvadora de Dios, a favor de los pobres y marginados.

\section{La muerte de Jesús como martirio}

Si bien el NT no aplica a Jesús el título de mártir, sí hay testificación de la experiencia de martirio. En relación al concepto, martirio viene de mártir que significa, a su vez, la persona que es testigo. En la tradición cristiana, el nombre de mártir se aplica exclusivamente a la persona que da testimonio con su sangre, esto es, da testimonio con la entrega de la propia vida (LeónDufour, 1982, p.513).

La relación entre la persona de Jesús y el martirio, en cuanto decisión cristiana, se funda en el hecho de que el mártir sigue el ejemplo de Jesucristo. Cristo es Alguien que da la vida por los hermanos; con su muerte da testimonio supremo de fidelidad a la misión que le fue confiada por el Padre (León-Dufour, 1982, p.514). Precisamente, el dar la vida a favor de los hombres es lo que permite llevar a cabo una interpretación martirial de la muerte de Jesús. Él es alguien que da testimonio con su sangre de la voluntad amorosa y misericordiosa de Dios para con los pobres, pecadores y marginados. 
Respecto de su muerte como martirio, Sobrino plantea que, de acuerdo al relato neotestamentario, se pueden reconocer dos líneas de interpretación. La primera línea apunta a la cuestión de por qué matan a Jesús y la segunda a la cuestión de por qué muere Jesús. Ambas se fundan en el kerigma primitivo. El kerigma primitivo, de versión histórica, sostiene que los que mataron a Jesús son el mismo tipo de persona que, a lo largo de la historia de Israel, han matado a los profetas (cf. 1Tes 2,15). El kerigma primitivo de versión teologal declara que la muerte de Jesús está en directa relación con la voluntad del Padre; Jesús fue entregado de acuerdo al designio y al previo conocimiento de Dios (cf. Hch 2,23). Sea cual sea la línea que se siga, no se puede descartar que ambas orientaciones kerigmáticas dejan al descubierto que a Jesús le quitan la vida, por lo que no se puede negar que ha muerto de manera violenta.

Por lo demás, los evangelios expresan abiertamente que Jesús es un hombre de conflictos. Es Alguien que genera simpatía y hostilidad. Como destaca Sobrino, el evangelio de Lucas, al narrar el inicio de la misión de Jesús, ya en sus primeros capítulos, deja en evidencia la primera agresión hacia Jesús. Lo mismo hace Marcos. En el relato acerca de las controversias entre Jesús y los fariseos, después de curar en día sábado, afirma que los oponentes del mismo se confabularon con los herodianos para acordar eliminarle (cf. Mc 3,6). Por tanto, es evidente en los evangelios el hecho de que Jesús es perseguido por sus contemporáneos.

La misma persecución a Jesús deja en evidencia que las razones están dadas por su insistencia en requerir un trato digno a los más débiles y marginados. Sobrino destaca que el hostigamiento a Jesús fue una realidad permanente y progresiva durante todo el tiempo en que llevó a cabo su ministerio; que los persecutores son grupos determinados de la sociedad, que ejercen algún tipo de poder -sea político, económico, religioso o socialy para quienes la actividad pública de Jesús se convierte en una amenaza. Asimismo, las razones que se aducen para llevar a cabo su persecución son las denuncias que el mismo Jesús hace contra el poder opresor del pueblo pobre y pecador; Jesús se enfrenta a los que justifican el ejercicio de su opresión en nombre de Dios. Por lo tanto, la persecución de la que es objeto Jesús no es algo accidental, sino que él mismo lo origina y lo provoca. Jesús es consciente de un posible desenlace fatal; él sabe del poder que tiene el Sanedrín y los romanos para darle muerte y, con todo, se mantiene firme 
en el hostigamiento. Se sabe libre ante cualquier tipo de poder y expresa un amor incondicional hacia el pueblo pobre, sufrido y pecador; la fidelidad a Dios y su misericordia por el pueblo, y en él, a la humanidad, cuentan mucho más que cualquier acuerdo favorable sólo a él. Es aquí cuando la muerte en cruz de Jesús se entiende sobre la base del designio de Dios, puesto que es precisamente en lo escandaloso de la cruz donde se manifiesta lo positivo de la salvación que Dios quiere para la humanidad.

La muerte en cruz de Jesús, ya sea porque cumple la voluntad del Padre como porque vive el rechazo de los que matan a los profetas, es el camino obligado cuando se trata de dar vigencia a una norma de Dios instituida desde el principio, la de que todos vivan en la dignidad de ser hijos de un mismo Padre. Con la muerte en cruz Jesús demuestra que ha estado siempre dispuesto a llegar hasta las últimas consecuencias; da su vida porque se erija en medio de la historia de la humanidad la voluntad originaria de Dios: la fraternidad.

\section{EL PUEBLO CRUCIFICADO A IMAGEN DE JESUCRISTO, EL SIERVO SUFRIENTE}

Sobrino señala que los teólogos latinoamericanos perciben una afinidad espontánea entre la agobiante realidad del pueblo y la figura sufriente del siervo. Cuando la cristología latinoamericana habla de los pueblos crucificados y lo vincula al siervo doliente de Yahvé es porque se busca desarrollar una teología a partir de la historia sufriente de los habitantes del continente. Esta cristología asume la originaria intuición de Mons. Oscar Romero e Ignacio Ellacuría, quienes ven una correspondencia entre el pueblo crucificado, Cristo crucificado y la figura del siervo de Yahvé sufriente 3 .

3 Todas las veces que Sobrino habla de este tema, señala que los primeros en desarrollar la relación entre el siervo de Yahvé y el pueblo crucificado fueron Mons. Oscar Romero e Ignacio Ellacuría. El primero, Mons. Romero, se refirió a los campesinos llamándolos de "el divino traspasado". Y Ellacuría es quien aplica al pueblo, después de conocer la realidad de El Salvador, realidad de pobreza, injusticia, opresión, represión y guerra, el título de "pueblo crucificado". Para ambos, esa manera de interpretar la realidad fue una idea central y permanente de su visión de la historia y de su comprensión de la fe. Cf. J. Sobrino, Onde está Deus? (Editora Sinodal, San Leopoldo, 2007) 86-87. 
En el contexto de la historia teológico-eclesial del continente, se ha enfatizado el sentido personal o individual del sufrimiento y la muerte en cruz de Jesucristo. El pensamiento cristológico latinoamericano retoma y distingue, especialmente, el sentido comunitario-eclesial del cuerpo de Jesús, que al igual que él vive la experiencia de la pasión y muerte. Esta línea de interpretación se inserta en la idea cristológico-eclesial de Pablo, quien desarrolla el tema del cuerpo de Cristo (cf. 1Cor 12,12ss). Siguiendo esa dirección, la cristología latinoamericana enfatiza que Jesucristo tiene un cuerpo comunitario-eclesial que no sólo está en la historia sino que hace historia, y que por lo mismo cabe interrogarse si ese cuerpo eclesial participa también y cómo participa de la crucifixión y muerte de Cristo.

Sobrino acentúa dicha línea de cuerpo. Afirma que es necesario hablar teológicamente de pueblos crucificados, porque decir cruz es decir muerte en clave cristológica. La muerte en cruz que sufre el pueblo es el de la pobreza, ya que ésta, en su persistente actualidad, mantiene al pueblo destinado a morir antes de tiempo. Se trata, por tanto, de una forma de muerte que el pueblo, asevera el teólogo, vive a dos ritmos; uno primero es el que se desarrolla a ritmo lento cuando la gente no puede acceder a la educación, a una vivienda digna y a la salud; el segundo se desarrolla a un ritmo más rápido, porque se trata de una muerte rápida y brutal en la que, por defender sus derechos, el pueblo es reprimido y asesinado (Sobrino, 1992, p.85).

El AT expone, en el cántico de Isaías, la figura del siervo de Yahvé como un "varón de dolores, acostumbrado al sufrimiento" $(53,3)$. Sobrino plantea que la teologización latinoamericana del pueblo crucificado se fundamenta, precisamente, en esta declaración sobre el siervo que hace el profeta Isaías. Así como el siervo es un varón acostumbrado al sufrimiento, de la misma manera el pueblo pobre llega a ver como una condición normal del hombre la realidad en la que vive; ellos definen como normal el dolor de la enfermedad, del analfabetismo, de las frustraciones antes que las necesidad básicas no satisfechas, del sufrimiento que padecen por años. Tales sufrimientos se agudizan si los pobres toman la decisión de instaurar, para sí mismos, la justicia y el derecho, al igual como le sucede al siervo de Yahvé (Is 42,4-7). Frente al comportamiento de reivindicación de la propia dignidad y de los propios derechos, el pueblo es condenado a ser reo de muerte, a ser sujeto de represión y a recibir como sentencia la muerte. 
$\mathrm{Al}$ igual que el siervo sufriente, asevera Sobrino, el pueblo adquiere un rostro desfigurado, porque carga con la fealdad de la pobreza, de las torturas, de los decapitados, de los quemados de ácido. De la misma manera como el desfigurado siervo de Yahvé que no tiene aspecto de hombre ni de ser humano, el pueblo pobre, desfigurado por la pobreza, suscita el asco y el desprecio de sus contemporáneos. Los pobres son despreciados y desestimados por los demás, porque al confrontarse y constatar sus sufrimientos, se apaga la felicidad de los que dan origen a la fealdad del pueblo pobre.

Por lo demás, todo eso resulta más contradictorio, afirma el teólogo salvadoreńo, cuando el sufrimiento de los pobres se interpreta como resultado de la voluntad de Dios, cuando se condena a los pobres en nombre de Dios y cuando se declara que sus sufrimientos son el resultado de haber sido heridos por Dios mismo a causa de sus pecados (Sobrino, 1991, p.324). Eso posibilita, muchas veces, avalar la institucionalización de la injusticia y de la violencia hacia el pueblo. De ahí que la palabra "cruz", desde el ámbito religioso, se convierte en un lenguaje útil y necesario para interpretar el dolor del pueblo, porque permite reconocer la cercanía y la salvación de Dios como un acontecimiento que llega también a los pobres.

Se puede preguntar en qué medida el sufrimiento del pueblo alcanza la justicia para el mismo pueblo pobre y marginado. La respuesta, en primera instancia, puede arrojar una negativa: en nada. Pero si el sufrimiento del pueblo se inserta en el sufrimiento de Jesucristo, entonces adquiere una comprensión que trasciende lo meramente humano. Los cristianos, como cuerpo de Cristo, asumen, en medio de la injusticia y desde la cruz, el sentido de reino que posee la historia cuando se procura vivirla desde la voluntad salvadora, de don y de restauración de Dios. Así, la crucifixión del pueblo, resultado del sufrimiento obtenido por el maltrato dado, declara dos cosas: de una parte, muestra la realidad de pecado de una sociedad injusta y, de otra, reafirma la actualidad del reino y la acción de Dios en medio de dicha realidad. Es precisamente a través de la cruz de Jesús que se prolonga en la experiencia de cruz del pueblo, que la esperanza cristiana cobra fuerza y hace patente la gracia salvadora de Dios a favor del pueblo sufrido y marginado de América Latina. 


\section{LA VIDA TRIUNFA SOBRE LA MUERTE}

El pensamiento cristológico latinoamericano da lugar a la relación entre justicia y resurrección, en el sentido de que la fe en la "resurrección de los muertos", dado por la resurrección de Jesús, implica cree que dicha resurrección alcanza, a su vez, la justicia de las víctimas.

La relación entre resurrección y justicia la expone Sobrino en la línea de que el principio teológico que posibilita esta interpretación consiste en la afirmación de que "Dios resucitó a un crucificado". Esa es la experiencia fundante de la fe cristiana y es la esperanza del pueblo crucificado (Sobrino, 1999, p.70).

El kerigma primitivo sustenta dicha relación. En la predicación de la primitiva comunidad se anuncia la resurrección de Jesús con base en dos hechos; uno primero, que los judíos mataron a Jesús clavándole en una cruz a manos de los impíos, y, segundo, que Dios resucitó al crucificado y lo libró del Hades (cf. Hch 2,23-24). Este anuncio de la primitiva comunidad permite entender que la resurrección de Jesús es la "respuesta de Dios a la acción injusta y criminosa de los seres humanos". Se trata de la respuesta de Dios en relación con la causa de muerte de Jesús. No se está afirmando la resurrección de cualquier persona, sino de la de Jesús de Nazaret; Dios resucitó al que "anunció el reino de Dios a los pobres y los defendió, que denunció y desenmascaró a los opresores, y por ellos fue perseguido, condenado a muerte y ejecutado" (Sobrino, 2008, p.150).

En el contexto de la cristología latinoamericana, la resurrección se interpreta no únicamente en relación con la superación de la muerte, sino, y principalmente, en la perspectiva teológica de que por la resurrección Jesús vive de manera permanente.

Sobrino plantea que ya en el AT se entiende al siervo de Yahvé como aquel que está puesto para que sea "luz de las naciones" (Is 42,6; 49,6). A Jesús Dios lo ha resucitado para que todos resucitemos en él. Así también, los crucificados participan de la resurrección de Jesús y su testimonio se torna luz que ilumina la verdad de lo que son, de lo que viven y de lo promueven los pobres. La participación en la resurrección de Jesús dilucida la cruz; así, 
el crucificado -Jesús- y los crucificados - pueblo- se convierten en luz para la verdad de la injusticia que caracteriza la vida en sociedad.

Además de ser luz, entender que los crucificados participan de la resurrección de Jesús se convierte en un signo de esperanza para el pueblo. Así como Jesús muere por amor al Padre y a los hombre, los crucificados dan su vida por amor a sus hermanos. Este es el punto de inflexión en donde convergen la cruz y la resurrección. Ahí donde la muerte y la crucifixión es fruto de la entrega por amor a los demás, ahí es donde surge el sentido de la esperanza en la resurrección. La resurrección de Jesús, que es la resurrección de un crucificado, revela el significado salvador y liberador que alcanza la superación del pecado, la marginación y la injusticia que viven los pobres. Hay esperanza en la resurrección cuando la historia de la humanidad, y en particular la de América Latina, se abre a la gracia que sana de raíz lo que se opone a la gratuita intervención amorosa y misericordiosa de Dios.

\section{REFLEXIONES FINALES: A FAVOR DE LOS POBRES Y MARGINADOS}

En la actualidad histórica, los pobres y marginados siguen ocupando un lugar central a la hora de definir el ser y hacer de América Latina. Respecto de sus habitantes: ¿quiénes son los pobres en Latinoamérica?, ¿son las mujeres, son los indígenas, son los niños, son los inmigrantes? En relación al hacer: ¿quiénes cuentan en América Latina?, ¿los acreedores de bienes, principalmente?

Desde la perspectiva teológica, anunciar a Jesucristo y examinar la fe que se traduce en su seguimiento, implica atender al "todo" de América Latina. Sin embargo, sigue siendo necesario discernir el lugar desde dónde se plantea el mensaje y se expone la praxis de Jesucristo. La cristología latinoamericana entiende que el punto de partida debe ser siempre el que definió Jesús: los pobres. Al dar inicio, desde los pobres, a la instauración del reino en medio de la historia, Jesús evidencia para todos el principio activo desde el cual actúa Dios. Tanto Jesús como el reino atestiguan que Dios interviene en la historia desde el abajamiento, el despojo y la solidaridad. Por tanto, decir 
justicia y decir martirio le otorga sentido al anuncio actual del Evangelio, en cuanto Buena noticia.

La fe cristiana afirma que Dios en Jesucristo salva a la humanidad. En América Latina, decir que con Jesucristo llega la salvación exige traducirlo al contexto, a la realidad histórico-social: ¿cómo declarar la salvación y el amor misericordioso de Dios a pueblos que viven en pobreza y marginación? Si Dios salva, ¿de qué los salva?, y si es misericordioso ¿qué hace con su realidad humana y social?, ¿en qué medida hace sentido a estos pueblos anunciar el amor salvífico de Dios?

Los cristianos de Latinoamérica, definidos por la fe y seguimiento a Jesucristo, se preguntan por el significado de la muerte de Jesús en una realidad histórica, marcada por el pecado de la pobreza y de la marginación, que exige conversión. Una manera de dar respuesta a los interrogantes y de anunciar a Jesucristo en el continente, ha sido y sigue siendo la perspectiva de justicia y de martirio.

Si se retoma su significado general, justicia refiere al orden en el que se desarrollan las relaciones humanas, y el martirio se define por el testimonio que da alguien con la propia sangre. Ambos elementos son expresión de dos realidades humano-cristiana que se manifiestan en la praxis de Jesús y en la vida de los cristianos.

Jesucristo trae consigo una salvación que, en el contexto de vida de los pueblos latinoamericanos, asume la comprensión de justicia y martirio. La experiencia cristiana manifiesta que la voluntad de Dios, hacia cuyo cumplimiento se dirige la salvación, consiste en que las personas y los pueblos vivan la vida plena que expone y representa Jesús. Él expresa que Dios es justo y que quiere la justicia y que por eso se ha comprometido con la humanidad por medio de la instauración del reino. Por tanto, el reino de Dios y lo que él comporta manifiesta la dirección desde la cual deben orientarse las relaciones humanas, ya sea en su configuración de sociedad o de comunidad. Dicha dirección comprende, por una parte, la aceptación de la iniciativa de Dios de disponer el modo como los seres humanos conviven entre sí; de otra, que esa dirección tiene como su punto de partida la realidad sufriente de los pobres y marginados. 
Sin embargo, la propuesta del reino de Dios que hace Jesús y que establece el orden de las relaciones humanas entre sí, no es aceptado de parte de sus contemporáneos ni por los que dirigen el sistema social establecido, por lo tanto Jesús debe morir. Dicha propuesta tampoco se acepta por las sociedades contemporáneas a los cristianos que lo siguen anunciando, de ahí que la teología latinoamericana hable de pueblos crucificados.

Ha habido y hay en el continente personas que siguen a Jesús y que están dispuestos de dar su vida para desenmascarar y erradicar el pecado de la pobreza y la marginación que subyuga a los pueblos; pero eso no ha sido posible y, al parecer, no lo es sin asumir la crucifixión y la muerte.

Así como la pobreza, el martirio también es una realidad concreta en el proceso histórico-social y cristiano de América Latina. Y es precisamente por eso que la esperanza llega a ser una realidad para los pobres y sufridos de nuestra tierra, porque se sustenta sobre la base de un compromiso de entrega por amor de los cristianos, que sustenta el potencial humanizador y evangelizador de Latinoamérica.

La esperanza, como lo expone Sobrino, posee el fundamento cristológico de la resurrección de Jesús. La instauración del reino de Dios va unido al triunfo de la vida sobre la muerte. El significado del triunfo sobre la muerte lo ha iniciado Jesús, y lo continúa el testimonio de sus discípulos y seguidores, a través de los tiempos. La entrega de la vida en la cruz, que realiza Jesús, es la vía de la irrupción de lo escatológico en la historia y en la realidad. Por tanto, la resurrección es, para los cristianos inmersos en la realidad latinoamericana, la respuesta creyente-cristiana de que la justicia y el martirio son el modo de vivir la esperanza y de alcanzar la victoria contra la negatividad del pecado en la historia y en la vida de la humanidad.

\section{LISTA DE REFERENCIAS}

Abbagnano, N. (2007). Dicionário de Filosofia. Edição revista e ampliada. São Paulo: Martins Fontes.

Atria, F. et al. (2013). El otro modelo. Del orden neoliberal al régimen de lo público. Santiago de Chile: Debate. 
II Conferencia General del Episcopado Latinoamericano (1968). Documentos finales de Medellín. Buenos Aires: Ediciones Paulinas.

II Conferencia General del Episcopado Latinoamericano (2007). Aparecida. Documento conclusivo. Santiago de Chile.

León-Dufour. X. (1982). Vocabulario de teología bíblica. Barcelona: Editorial Herder.

Lesbanpin, I. (2006). O neoliberalismo e o proceso de exclusão. En Soter e Amerincia (Orgs.) Caminhos da Igreja na America Latina e no Caribe. São Paulo: Paulinas, 55-64.

Medina, D. A. (2007). La justicia en el Nuevo Testamento. Revista Labor Theologicus, (38-39), 101-129.

Zaffaroni, C. (2006). Processos de empobrecimiento na América Latina. En Soter e Amerincia (Orgs.) Caminhos da Igreja na America Latina e no Caribe. São Paulo: Paulinas, 65-78.

Sobrino, Jon. (1991). Jesucristo liberador. Madrid: Editorial Trotta.

Sobrino, Jon. (1992). El principio-misericordia. Bajar de la cruz a los pueblos crucificados. Santander: Sal Terrae.

Sobrino, Jon. (1999). La fe en Jesucristo. Ensayo desde las victimas. Madrid: Editorial Trotta.

Sobrino, Jon. (2007). Onde está Deus? San Leopoldo: Editora Sinodal.

Sobrino, Jon. (2008). Foras dos pobres não há salvacão. São Paulo: Paulinas. 